\title{
BMJ Open Can the Healthy Primary School of the Future offer perspective in the ongoing obesity epidemic in young children? A Dutch quasi-experimental study
}

To cite: Bartelink NHM, van Assema P, Kremers SPJ, et al. Can the Healthy Primary School of the Future offer perspective in the ongoing obesity epidemic in young children? A Dutch quasiexperimental study. BMJ Open 2019;9:e030676. doi:10.1136/ bmjopen-2019-030676

- Prepublication history and additional material for this paper are available online. To view these files, please visit the journal online (http://dx.doi. org/10.1136/bmjopen-2019030676).

Received 26 March 2019 Revised 23 August 2019 Accepted 01 October 2019

D) Check for updates

(c) Author(s) (or their employer(s)) 2019. Re-use permitted under CC BY-NC. No commercial re-use. See rights and permissions. Published by BMJ.

For numbered affiliations see end of article.

Correspondence to Nina H M Bartelink;

n.bartelink@

maastrichtuniversity.nl

\section{ABSTRACT}

Objectives Schools play an important role in promoting healthy behaviours in children and can offer perspective in the ongoing obesity epidemic. The 'Healthy Primary School of the Future' (HPSF) aims to improve children's health and well-being by enhancing school health promotion. The current study aims to assess the effect of HPSF on children's body mass index (BMI) z-score after 1 and 2 years follow-up and to investigate whether HPSF has different effects within specific subgroups of children. Design A longitudinal quasi-experimental design. Setting Four intervention and four control schools participated; located in a low socioeconomic status region in the Netherlands.

Participants 1676 children (aged 4-12 years). Interventions HPSF uses a contextual systems approach and includes health-promoting changes in the school. Central to HPSF is the provision of a daily healthy lunch and structured physical activity sessions each day. Two intervention schools implemented both changes (full HPSF), two intervention schools implemented only the physical activity change (partial HPSF).

Main outcome measures BMI z-score, determined by measurements of children's height and weight at baseline, after 1 and 2 years follow-up.

Results The intervention effect was significant after 1 year follow-up in the partial HPSF (standardised effect size $(E S)=-0.05)$, not significant in the full HPSF $(E S=-0.04)$. After 2 years follow-up, BMl z-score had significantly decreased in children of both the full HPSF ( $E S=-0.08)$ and the partial HPSF $(E S=-0.07)$ compared with children of the control schools, whose mean BMI z-score increased from baseline to 2 years. None of the potential effect modifiers (gender, baseline study year, socioeconomic status and baseline weight status) were significant. Conclusions HPSF was effective after 1 and 2 years follow-up in lowering children's BMI z-scores. No specific subgroups of children could be identified who benefitted more from the intervention.

Trial registration number NCT02800616.

\section{INTRODUCTION}

Overweight and obesity can lead to health problems, such as type 2 diabetes,
Strengths and limitations of this study

- Due to the longitudinal quasi-experimental study design, we were able to test the effectiveness in terms of differences in children's health behaviours between the three school groups over time, and were also able to enrol schools on the basis of motivation, which reflects the real-life situation of school health promotion.

- Since the lack of randomisation could have resulted in confounding bias, we controlled for baseline body mass index (BMI) z-score, gender, study year at T0, socioeconomic status score and ethnicity in all analyses.

- The high number of children enrolled in the measurements, the low drop-out rate and the objectively measured BMI were strengths of this study.

- Due to some missing data, multiple imputations were used and a sensitivity analysis was conducted, where only complete cases were included.

- Participants did not significantly differ from nonresponders in the participating schools and other children in the region with regard to health and lifestyle.

cardiovascular diseases and psychological problems (eg, low self-esteem). ${ }^{12}$ Globally, the prevalence of overweight and obesity among children and adolescents (aged 5-19) has risen dramatically from $4 \%$ in 1975 to more than $18 \%$ in $2016 .{ }^{34}$ The prevalence is highest among children with a low socioeconomic background. ${ }^{5}$ In the Netherlands, the prevalence of childhood overweight and obesity has also increased in the last decennia: $13 \%-15 \%$ of children (aged 2-21 years) are overweight, and $1.8 \%-2.2 \%$ are classified as obese, which is a two to threefold increase compared with $1980 .{ }^{6}$ The ongoing epidemic increase is particularly caused by unhealthy behaviours, such as unhealthy dietary intake and low levels of physical activity (PA). ${ }^{7}$ The 
health behaviours of children in the Netherlands are suboptimal. For example, $42 \%$ of children (aged 4-9 years) consume at least $150 \mathrm{~g}$ of fruit per day, which drops to $20 \%$ for $9-12$ years old. ${ }^{8}$ Regarding PA, only half ( $48 \%$ ) of Dutch children (aged 4-12) meet the guidelines for PA of $60 \mathrm{~min}$ of moderate-to-vigorous PA per day. ${ }^{9}$ Unhealthy behaviours at a young age often track into adulthood ${ }^{10}$ and are related to health and psychosocial problems, reduced quality of life, higher healthcare costs, lower educational achievement and labour participation. ${ }^{11-13}$ A vicious circle is emerging, transferring problems, such as obesity, from one generation to the next. ${ }^{14}$ Promoting healthy behaviours at an early age may help to improve children's health on the short and long run. ${ }^{10}$ Moreover, promoting health behaviours could also lead to better educational and academic achievements, which have been found to be related to improved health in later life as well. ${ }^{15}$

Schools can play an important role in promoting healthy behaviours in children since a significant proportion of a child's day is spent there and they reach all children. ${ }^{16-18}$ As such, school-based interventions may be an important instrument to offer perspective in the ongoing obesity epidemic in young children. Many different school-based interventions (eg, related to education, environment, policy and monitoring) have been implemented to integrate health into the school system and reduce childhood overweight and obesity. The meta-analysis of both CookCottone $e t a l$ and Oosterhoff $e t$ al found that the significant effect of school-based interventions on children's body mass index (BMI) z-score had an overall weighted effect size (ES) of approximately $-0.05 .^{19}{ }^{20}$ Several studies indicated that effects are often hampered by underestimation of the challenges associated with implementing meaningful changes to the school system. ${ }^{21-23}$ These challenges occur because an intervention always interacts with the specific school context. ${ }^{22}{ }^{23}$ Therefore, solutions for the challenges associated with changing school systems vary between schools as they all have their own dynamics. ${ }^{22-24}$ Consequently, an intervention can be seen as an attempt to positively disrupt the prior functioning of a school system. ${ }^{25} 26$ Some other reviews stated that specific subgroups of children benefit more from a school-based intervention. The review of Stewart-Brown ${ }^{27}$ found that several studies indicated gender-specific results, with some school-based interventions being more effective in girls and others in boys. Age-specific effects were often found, with some interventions being more effective in older children and others in younger children. ${ }^{27}$ Cook-Cottone et al found that children's socioeconomic background can be an influential factor and that children already having overweight can respond more slowly or to a lesser extent to school-based interventions than children with a healthy weight. ${ }^{19}$

A Dutch initiative that embraces a contextual systems approach is the 'Healthy Primary School of the Future' (HPSF). ${ }^{28} 29$ HPSF aims to improve the health and well-being of all children in the school which should contribute to a healthier future generation and thereby offer perspective in the ongoing obesity epidemic. ${ }^{30} \mathrm{HPSF}$ includes top-down and bottom-up processes to create health-promoting changes in the school. Two changes were initiated to create some form of positive disruption in the school: (1) providing a free healthy lunch each day and (2) daily structured PA sessions after lunch. While in other national school systems this may represent usual practice, these changes are hypothesised as disruptive to the Dutch school system because the provision of school lunches and structured PA sessions are not usual practice in Dutch schools. The two changes aimed to create momentum to implement additional health-promoting changes in the school, such as a healthy school policy or creating a PA-friendly schoolyard. All changes together should favourably affect the health behaviours of all school children, which should lead to improved health and a more normal weight status. ${ }^{28} 29$

The aim of the current study was to assess the effect of HPSF on children's BMI z-score after 1 and 2 years follow-up and to investigate whether HPSF has different effects within specific subgroups of children. The current study is part of an overall study to investigate HPSF. The overall study has a broad scope and includes a multidisciplinary research group, which focuses on many different outcomes, such as children's health behaviours, educational achievements and well-being. The studies that have been published previously, focused on the implementation process of HPSF $^{31}$ and the effects of HPSF on children's dietary and PA behaviours. ${ }^{32}$ The current study explicitly concentrates on children's BMI z-score to focus in much detail on the primary outcome as described in the study design of Willeboordse $e t a l^{28}$

\section{METHODS}

\section{Study design}

The current study had a longitudinal quasi-experimental design with four intervention schools and four control schools, which maintained the school curriculum that is currently common practice in the Netherlands. Ethical approval (14N-142) was given by the Zuyderland Medical Ethics Committee located in Heerlen (Parkstad, the Netherlands). Parents had to sign an informed consent form to participate in all measurements for themselves and their child(ren). Measurements were conducted in September to November 2015 (T0), 2016 (T1) and 2017 (T2). A detailed description of the study and the power calculation is reported in Willeboordse $e t a l .^{28}$

\section{The Healthy Primary School of the Future}

Three collaborating organisations, that is, the regional educational board 'Movare', the regional Public Health Services and Maastricht University, developed the idea for HPSF. $^{28}$ In March 2013, 12 out of 53 schools governed by the Movare educational board were informed about the initiative. Four schools gave their initial consent and spent a whole school year (2014/2015) creating 
bottom-up support for HPSF. Two of the four intervention schools decided to implement both the daily lunch and the structured PA sessions and are referred to as the 'full HPSF'. The other two intervention schools decided to only implement the structured PA sessions, and are referred to as the 'partial HPSF'. All schools could implement additional health-promoting changes that fit their school context. ${ }^{29} 31$ The full HPSF improved their health policy, provided water bottles to all children and provided an educational lunch once a week. The partial HPSF did not implement additional health-promoting changes.

Implementation started in all four intervention schools in November 2015. The time for having lunch (in the full HPSF) was increased to 20-30 min. The total lunch break time in these schools was prolonged by about $60 \mathrm{~min}$. For this reason, the school day was extended: children of the full HPSF attend school to approximately 15:30/15:45 instead of 15:00. A dietician of the caterer developed a lunch menu cycle that changed every 10 weeks, in which at least $80 \%$ of the products met the advice of the Dutch Health Council. ${ }^{33}$ A mid-morning snack, consisting of fruits and/or nuts, was also provided. The lunch, a breadbased cold meal, was typically Dutch. During lunch break time, the children participated several times a week in structured PA sessions; one or two times per week they could participate in cultural activities. The PA sessions were carried out in the schoolyard and, when available and needed, in parks, forest and/or sports hall in the neighbourhood. All schools collaborated with sport clubs or other external partners to offer specific activities as well. Since the two changes were contextualised bottom-up, this resulted in some differences between schools in the form of the changes; the content remained comparable.

The two changes, that is, providing daily a free healthy lunch and structured PA sessions after lunch, were both led by external pedagogical employees provided by childcare organisations to not increase the workload of teachers even further. This integration of the childcare organisation during school hours is not to provide a temporary solution, but to change the school's organisation in a sustainable way. The aim for the future is to bring school and childcare more together and thereby create an integrated day for children, whereby children are supervised by the same people prior, during and after school hours. Employees of sports and leisure organisations supported the external pedagogical employees during implementation when needed, and after a year they provided a training course ( 8 sessions of 2 hours) to supply them with additional tools for how to motivate children for active participation during the PA sessions. A health promoter from the regional Public Health Services was assigned to each school to provide support when needed. In this study, researchers from Maastricht University monitored and fed back results to the schools to support the processes of change. Funding for implementation of HPSF is provided by the provincial authorities until the end of 2019. However, the four schools have committed to continued implementation after 2019 and make the changes sustainable in their school.

\section{Patient and public involvement}

Public involvement was a key feature of HPSF. This intervention intended to establish a cocreation movement in schools aimed at the systematic incorporation of health and well-being. The two top-down changes and the additional health-promoting changes were developed and contextualised by bottom-up involvement. Teachers and parents were involved from the start in the adoption decision and the process of adapting the several changes into the school context. Moreover, all four schools used a children voice group, with representatives from each class in school, to get insight into the opinion of children regarding HPSF. In this way, the experiences of children were being heard and the changes could be further contextualised to fit better to the children's needs and wishes. Each of the four intervention schools selected a teacher as school coordinator, who managed HPSF in their school. Overarching, HPSF was led by an executive board with representatives of the three collaborating organisations: Movare, the regional Public Health Services and Maastricht University. They discussed the study design, the relevant outcome measures and the interpretation of the results. The representative of Movare advised explicitly on school and participant recruitment and the communication to schools. A project team was created with representatives of all partners involved: the four schools, Movare, regional Public Health Services, Maastricht University, the Limburg provincial authorities, childcare organisations, the caterer and sports and leisure organisations. No patients were involved in this study.

\section{Study population}

All intervention and control schools are situated in the Parkstad region in the southern part of the Netherlands. This region has a low average socioeconomic status (SES), and unhealthy lifestyle behaviours and overweight are highly prevalent compared with the rest of the Netherlands. ${ }^{34}$ More information on the recruitment of the schools has been described elsewhere. ${ }^{28}$ All children $(n=2326$ at T0) and their parents in the eight schools were invited to participate in the study. This included children from study year 1 to 8 (age 4-12 years), which is comparable to 2 years of Kindergarten and six primary school grades. Recruitment was done via information brochures for parents. In addition, the research team visited the classrooms to inform children about the study and encourage them to ask their parents for participation. ${ }^{28}$ Due to the dynamic population in the schools (new children enter and other children finish school each year), we focused in this study only on the children who were enrolled in the schools at baseline till the end of this 2-year study. The population of children included in this study were: at baseline (T0) children from study year 1 to 7 , at T1 children from study year 2 to 8 and at T2 children from study year 3 to 8 . Children of these study years who joined the 
study at T1 or T2 were included, even though no baseline data were available. Even though these children joined the study later, they were at baseline already participating in their school and thus also exposed to HPSF during the full 2 years of this study. Children who switched to other schools between 2015 and 2017 were excluded.

\section{Measurements}

In each school, the data were gathered annually during 1 week of measurements. Inter-rater variability was minimised by training researchers according to a strict protocol. ${ }^{28}$ Children's age, study year and gender were collected via the database of the educational board Movare. A digital questionnaire for parents was used to obtain information about the children's socioeconomic background and ethnicity. SES was calculated as the mean of standardised scores on maternal education level, paternal educational level and household income (adjusted for household size). ${ }^{35}$ The mean scores were categorised into low, middle and high-SES scores based on tertiles. Children's ethnicity was determined by the country of birth of both parents and divided into (1) Western background (including the Netherlands) and (2) non-Western background. ${ }^{36}$ If one of the parents was born in a non-Western country, the child's ethnicity was assigned to non-Western. The distinction between Western and non-Western was created because of differences in socioeconomic and cultural position between the two backgrounds. ${ }^{36}$

\section{BMI z-score}

Anthropometric measurements, that is, height, weight, hip and waist circumference, were conducted in children from study year 2 to 8 . The measurements were integrated in the school hours allocated to physical education. Weight was measured to the nearest $0.1 \mathrm{~kg}$ (Weighing Scale 803, Seca, Hamburg, Germany) and height was measured to the nearest $0.1 \mathrm{~cm}$ (Stadiometer 213, Seca, Birmingham, UK). Hip and waist circumference were measured with a measuring tape to the nearest $0.1 \mathrm{~cm}$ (model 201, Seca,) . Children were measured with light sports clothing and no shoes. All anthropometric measurements were performed twice, and a third measurement was conducted if the difference between the first two measurements exceeded a preset limit (weight $\geq 0.2 \mathrm{~kg}$, height $\geq 0.5 \mathrm{~cm}$, hip and waist circumference $\geq 1.0 \mathrm{~cm}$ ). Unfortunately, hip and waist circumference were excluded from further analyses due to measurement errors. BMI was assessed by height and weight; age and gender-specific BMI cut-off points were used to define overweight and obesity. ${ }^{37} \mathrm{BMI}$ z-scores were calculated by using Dutch reference values. ${ }^{6}$

\section{Statistical analyses}

Data were analysed using IBM SPSS Statistics for Windows (V.23.0). Pearson's $\mathrm{X}^{2}$ tests and analysis of variance tests were conducted to analyse the comparability of the observed participant characteristics among the full HPSF, the partial HPSF and control schools at baseline. Linear mixed-model analyses were used to assess the longitudinal intervention effects on the children's BMI z-score. Since measurements were repeated within participants, we used a two-level model with repeated measurements as the first level and participants as the second level, where an unstructured covariance structure was considered for the repeated measures. The fixed part of the model consisted of group (full HPSF, partial HPSF and Control), time (T0, T1, T2) and the interaction terms of group with time. We were not able to include class as a level in the model, because often several divisions of one class existed, for example, $4 \mathrm{a}$ or $4 \mathrm{~b}$, and children often did not have fixed class divisions for all years. All analyses were adjusted for gender, study year at baseline, SES and ethnicity. Missing covariates and BMI z-scores were imputed using multiple imputation method with fully conditional specification and 10 iterations, generating 50 complete datasets. Gender, study year at baseline, school type, ethnicity, SES score and BMI z-score were used to impute the missing data. We performed two sensitivity analyses. First, we replicated the analyses by only selecting the children who had no missing BMI z-score at all three time points (complete-case analysis). Second, we replicated the analyses while excluding children with an extremely low BMI z-score at baseline (BMI z-score $\leq-2$ ), to study the effects only in children for which a decrease in BMI z-score is favourable.

To study whether the intervention effects were similar for all subgroups of children, the following potential effect modifiers were considered: gender (boys/girls), study year at baseline (lower (1-4)/higher (5-8) grades), SES (low/middle/high) and baseline weight status (nonoverweight/overweight). To assess this potential effect modification, the interaction term group*time*effect modifier, with all corresponding two-way interactions, was added to the above mentioned model. If this interaction term was significant (here we used a significance level of 0.10 to deal with the fact that the power of a test for interaction is relatively low and we did not want to miss any effect modification), the intervention effects were reported for all categories of the effect modifier separately. For all other analyses, a two-sided $p \leq 0.05$ was considered statistically significant. Standardised ESs at each time point were included, which were defined as estimated mean difference at that time point (T1 or T2) divided by the square root of the residual variance at baseline (pooled over all three groups).

\section{RESULTS}

Of all children $(\mathrm{n}=2326)$ invited to participate in the (overall) study, $60.3 \%$ joined the study at baseline $(n=1403)$ (figure 1). Because of the study's dynamic population, a total of 1974 children and their parents participated in the study within the 2-year follow-up period (data collected at one time point at least). Due to the selection used for the current study, that is, only including the children who were in study year 1-7 at baseline, we included 


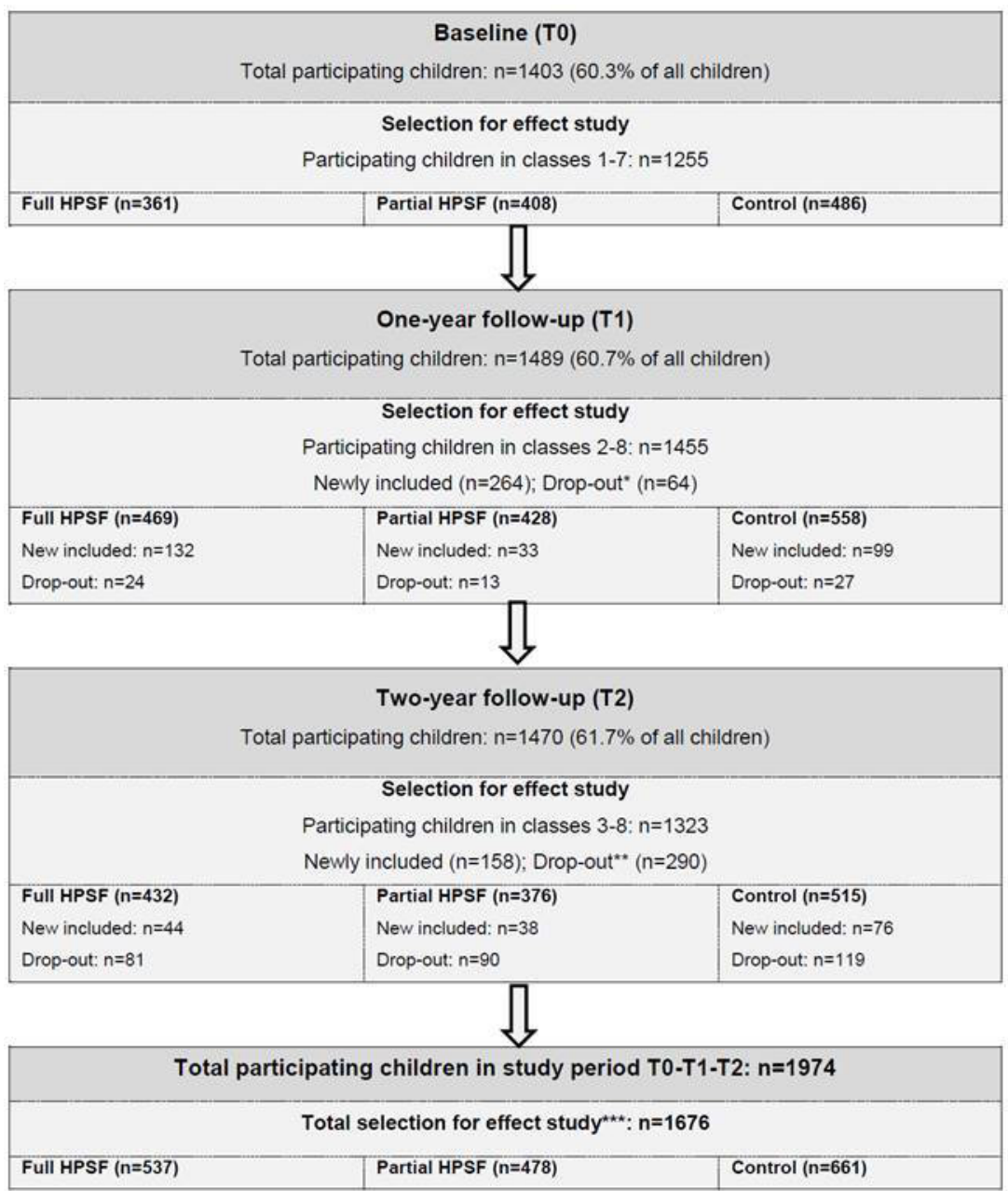

Figure 1 Flow chart. *Reasons for drop-out T1: switched to other include school $(n=2)$, other reasons, for example, moved away or actively stopped participation $(n=62)$. ${ }^{\star *}$ Reasons for drop-out T2: finished school $(n=228)$, switched to other included school $(n=17)$, other reasons, for example, moved away or actively stopped participation $(n=45)$. ${ }^{* *}$ Selection for effect study: at baseline (T0) children from study year one to seven, at T1 children from study year 2-8, and at T2 children from study year 3-8. HPSF, Healthy Primary School of the Future.

1676 children in the analysis. Of these children, $47.4 \%$ were boys, their mean age was 7.5 years old and $94.1 \%$ had a Western ethnicity (table 1 ). In total, $19.9 \%$ of these children suffered from overweight or obesity, which is higher compared with the national average of $13 \% .^{38}$ BMI z-scores at baseline differed significantly between the three school groups $(\mathrm{p}=0.034)$ : the average BMI $z$-score of children in the control schools $(z$-score $=0.232$ ) was higher compared with children in the full HPSF $(z$-score $=0.051$ ) and the partial HPSF ( $z$-score $=0.092$ ). Significantly more children suffered from overweight or obesity in these control schools $(24.1 \%)$ than the full HPSF $(16.5 \%)$ and the partial HPSF $(17.9 \%) \quad(p=0.006)$.

Observed data at $\mathrm{T} 1$ showed a decrease in BMI z-score compared with baseline in all three groups, with the full HPSF ( $\Delta$ z-score: -0.074$)$ and the partial HPSF $(\Delta z-$ score: -0.098 ) having the largest decrease, and control schools a smaller decrease $(\Delta \mathrm{z}$-score: -0.018$)$. At T2, a decrease in BMI z-score compared with baseline was observed in the full HPSF ( $\Delta$ z-score: -0.039 ) and the partial HPSF ( $\Delta$ z-score: -0.012 ), and an increase in the control schools $(\Delta z$-score: +0.058$)$ (figure 2$)$. The extent of observed increase or decrease at T1 and T2 compared with baseline of individual children in the three different groups is visualised in online supplementary figure S1. This figure shows that compared with the control schools, in the full and partial HPSF, a higher percentage of children had decreased BMI z-scores. This was particularly visible after 1-year follow-up. The figure also indicates that, on an individual level, mostly minimal to moderate changes $(-0.6 \leq \Delta$ z-score $\leq+0.6)$ were realised. The variation in changes increased over time, that is, the percentage of large and extreme decreases and increases was larger after 2-year follow-up compared with 1-year follow-up.

Mixed-model analyses were conducted to study the differences in effect among the three groups. The intervention effect was, compared with control schools, significant after 1-year follow-up in the partial HPSF $(\mathrm{ES}=-0.05)$, not significant in the full HPSF $(\mathrm{ES}=-0.04)$ (table 2). After 2 years follow-up, a significant intervention effect on children's BMI z-score was found in both 
Table 1 Characteristics of study sample at baseline (TO)

\begin{tabular}{|c|c|c|c|c|c|c|c|c|c|c|}
\hline & \multicolumn{2}{|l|}{ Total } & \multicolumn{2}{|c|}{ Full HPSF } & \multicolumn{2}{|c|}{ Partial HPSF } & \multicolumn{2}{|c|}{ Control } & \multirow[b]{2}{*}{$\begin{array}{l}X^{2} / F \\
\text { value }\end{array}$} & \multirow[b]{2}{*}{$P$ value } \\
\hline & $\mathbf{N}^{*}$ & $\begin{array}{l}\% / \\
\text { mean (土SD) }\end{array}$ & $\mathbf{N}$ & $\begin{array}{l}\% / \\
\text { mean (土SD) }\end{array}$ & $\mathbf{N}$ & $\begin{array}{l}\% / \\
\text { mean (土SD) }\end{array}$ & $\mathbf{N}$ & $\begin{array}{l}\% / \\
\text { mean (土SD) }\end{array}$ & & \\
\hline Age (years) & 1676 & $7.5( \pm 2.16)$ & 537 & $7.6( \pm 2.16)$ & 478 & $7.4( \pm 2.22)$ & 661 & $7.6( \pm 2.13)$ & 1.610 & 0.200 \\
\hline Study yearf & 1676 & $4.0( \pm 2.00)$ & 537 & $4.0( \pm 2.00)$ & 478 & $3.8( \pm 2.01)$ & 661 & $4.1( \pm 1.99)$ & 2.526 & 0.080 \\
\hline \multicolumn{11}{|l|}{ SES (\%) } \\
\hline Lowest tertile & 1117 & $32.6 \%$ & 361 & $28.8 \%$ & 365 & $32.3 \%$ & 391 & $36.3 \%$ & 5.636† & 0.228 \\
\hline Middle tertile & & $34.0 \%$ & & $35.7 \%$ & & $35.6 \%$ & & $30.9 \%$ & & \\
\hline Highest tertile & & $33.4 \%$ & & $35.5 \%$ & & $32.1 \%$ & & $32.7 \%$ & & \\
\hline
\end{tabular}

Bold $p$ value $=$ significant $(<0.05)$ difference.

*Observed N, missing data were due to later participation in the study, incomplete parent questionnaire, or because no height/weight was measured in study year 1 .

$\dagger \mathrm{X}^{2}$ test.

¥Study year 1-8 in Dutch system is comparable to 2 years of kindergarten followed by grades 1-6.

BMI, body mass index; HPSF, Healthy Primary School of the Future; SES, socioeconomic status.

versions of HPSF. Children's BMI z-score had decreased significantly more in the full HPSF $(\mathrm{ES}=-0.08)$ and the partial HPSF (ES=-0.07), compared with children of the control schools, whose estimated mean BMI z-score increased from baseline to 2 years as reported above. No significant difference in effect was found between the full and partial HPSF at T1 and T2. Both complete-case analyses $(\mathrm{n}=759)$ and the sensitivity analyses in which children with an extremely low BMI z-score at baseline were excluded $\left(\mathrm{N}_{\text {excluded }}=14\right)$, resulted in comparable ESs. None of the interaction terms of the potential effect modifiers, that is, gender, study year, SES and weight status, was significant (online supplementary table $\mathrm{S} 1$ ).

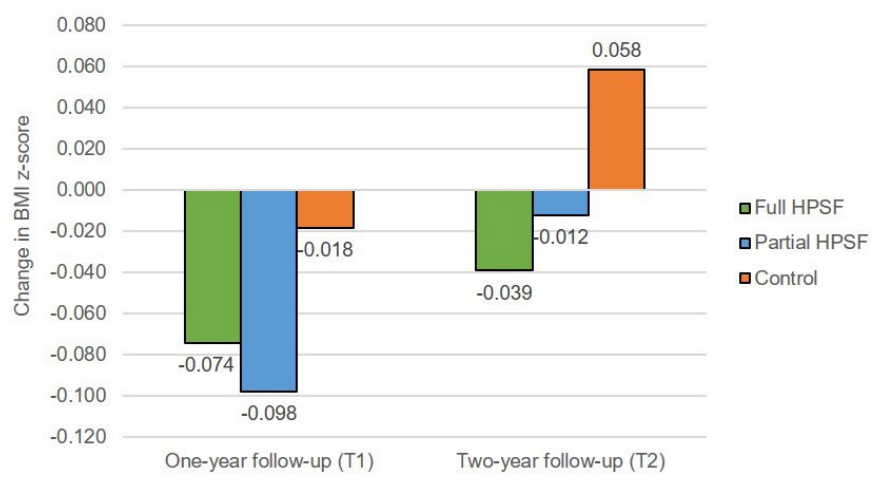

Figure 2 Observed change in children's BMI z-score at 1 and 2-year follow-up compared with baseline. BMI, body mass index; HPSF, Healthy Primary School of the Future.

\section{DISCUSSION}

This study assessed the effects of HPSF on children's BMI z-score after 1 and 2-year follow-up compared with children of control schools. The findings showed a favourable decreasing effect at T2 on children's BMI z-scores in both the full HPSF (standardised $\mathrm{ES}=-0.08$ ) and the partial HPSF (ES=-0.07) compared with control schools, where the BMI z-score actually increased at T2 compared with baseline. According to Lipsey's guidelines,${ }^{39}$ these findings can be indicated as a small effect (ES between 0 and 0.32). These small intervention effects are promising for three reasons: (1) they are already visible after 2 years of implementation, (2) they indicate a change in the increasing BMI trend observed in the control schools and (3) they are slightly higher than the ESs found in several meta-analyses regarding school-based interventions. ${ }^{19} 2040$ The decrease in BMI z-score found in this study in the full and partial HPSF can, therefore, be considered as a favourable and promising intervention effect. No significant differences were found between the full and partial HPSF. The main distinction between them was the provision of a healthy lunch. However, the process evaluation of Bartelink et al has shown that providing this lunch led to the implementation of additional health-promoting changes (eg, health promoting policy, educational lunch) ${ }^{31}$ Additional health-promoting changes were not implemented in the partial HPSF. ${ }^{31}$ However, since no significant differences were found between the full and partial HPSF, this might indicate that the differences between the two versions of HPSF did not have an additional favourable effect on the children's BMI z-score. 
Table 2 One and 2-year estimated intervention effects on children's BMI z-score*

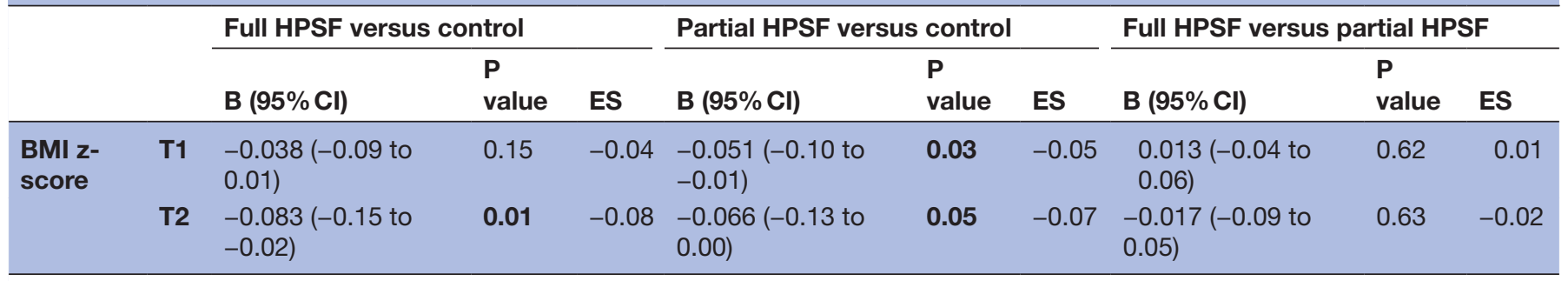

Bold $\mathrm{p}$ value $=$ significant $(<0.05)$ difference.

${ }^{*}$ Adjusted for baseline, gender, study year at TO, SES, and ethnicity.

BMI, body mass index; ES, effect size; HPSF, Healthy Primary School of the Future; SES, socioeconomic status.

The favourable effects on children's BMI z-scores seem to indicate that the children improved their health behaviours. Indeed, significant favourable intervention effects were found after 1 and 2-year follow-up for the full HPSF on children's dietary behaviours for, among others, school water consumption and lunch intake of vegetables and dairy products. ${ }^{32}$ Children's sedentary time and light PA significantly improved after 2years follow-up. Almost no significant favourable results on children's health behaviours were found in the partial HPSF. Since it is the coexistence and interaction of several nutrition and PA behaviours that results in a positive (or negative) energy balance and weight gain (or loss), ${ }^{41} 42$ the results suggest that many small improvements on several different health behaviours have occurred in the children of the partial HPSF, leading to the favourable effects on their BMI z-score.

Even though the effects of HPSF on children's BMI $\mathrm{z}$-score seem promising, it is important to realise that 2 years follow-up is too short to conclude that HPSF has led to sustainable changes. A longer follow-up period is needed to study whether the results found are not only due to the children's enthusiasm for and cooperation with the new changes in school, which might result in intervention effects that diminish after longer follow-up periods. This can be the reason for the smaller observed change scores after 2 years follow-up compared with after 1 year, shown in figure 2. On the other hand, the favourable results that are still found after 2 years follow-up might indicate that new habits and routines have developed in children's health behaviours. The latter is not easy to change and requires a shift in the social norms of all people in the school regarding 'normal' health behaviours. Therefore, further research into HPSF should investigate its longterm effects on children's BMI z-score. Other outcomes should also be investigated to study the effects of HPSF, including children's educational achievements and wellbeing and the cost-effectiveness of the intervention. This broader scope of the effects of HPSF is included in the overall study design and will be investigated by our multidisciplinary research group. ${ }^{28}$ The specific focus in the current study enabled us to investigate the effects of HPSF on children's BMI z-score in much more detail.
The second research question investigated whether HPSF has different effects within specific subgroups of children. Effect-modification analyses showed no significant interactions at T1 and T2. However, ESs give a better indication since the big difference in group sizes in the subgroups of, for example, children's weight status, influenced the $p$ value. All ESs showed similar patterns to the overall analyses. These results seem to indicate that no specific subgroups of children were found to benefit more from HPSF, which is promising as often schoolbased interventions only seem effective for specific subgroups. ${ }^{19} 27$ These results are especially promising when related to health inequalities, because even when interventions are successful in improving children's health, they may still increase health inequalities. This can happen when an intervention is of greater benefit to advantaged groups, for example, high SES, than to disadvantaged groups, for example, low SES. ${ }^{43}$ Given the results of the effect modification analyses, HPSF can be seen as an example of an intervention that does not seem to increase health inequalities among children. Further research with longer follow-up periods should investigate whether HPSF contributes to reducing the health inequalities.

\section{Strengths and limitations}

The longitudinal quasi-experimental design can be seen as a limitation of this study, since we were unable to (cluster-) randomise schools. However, due to this design, we were able to test the effectiveness in terms of differences in children's BMI z-scores between the three school groups over time, and were also able to enrol schools on the basis of motivation, which reflects the real-life situation of school health promotion. Moreover, participants did not significantly differ from non-responders in the participating schools and other children in the region with regard to health and lifestyle. ${ }^{44}$ The lack of randomisation could, however, have resulted in confounding bias. Therefore, we controlled for baseline BMI z-score, gender, study year at T0, SES score and ethnicity in all analyses. The significant differences in children's BMI z-scores at baseline between the three groups could indicate that children in the control schools are less open to change: their habits in unhealthy behaviours are stronger 
as they have already led to overweight or obesity. On the other hand, this difference, which we controlled for, may have resulted in an underestimation of the effect: more room for improvement existed for the children in the control schools compared with the full and partial HPSF.

Next, HPSF seemed to affect all children in the intervention schools. However, a decrease in BMI z-score might not be favourable for all of them, for example, when they already have an extremely low BMI z-score. Therefore, to ensure that the findings reflected the children for whom a decrease in BMI z-score is favourable, we conducted extra sensitivity analyses, in which we excluded the children with extremely low BMI z-scores at baseline. These analyses showed comparable results. The high number of children enrolled in the measurements, the low drop-out rate, and the objectively measured BMI were other strengths of this study. There were missing data because some participants did not participate from the start, other participants finished school before the last measurement period in 2017, the parental questionnaire was not completed, respondents skipped questions, or data could not be obtained due to the absence of the child. To deal with the missing data, multiple imputations were used, and a sensitivity analysis, in which only complete cases were included, was conducted. Completecase analysis showed similar results to the original analysis, which increased the reliability of the findings in this study.

\section{CONCLUSIONS}

Taking all the results and limitations into account, it can be concluded that HPSF was effective in lowering children's BMI z-scores after 1 and 2-year follow-up and no specific subgroups of children were found to benefit more from the intervention. Even though longer follow-up periods are needed to draw hard conclusions, both versions of the initiative seem promising in offering perspective in the ongoing obesity epidemic in young children.

\section{Author affiliations}

${ }^{1}$ Department of Health Promotion, Maastricht University, Maastricht, The Netherlands

${ }^{2}$ Department of Nutrition and Movement Sciences, Maastricht University, Maastricht, The Netherlands

${ }^{3}$ Department of Clinical Epidemiology and Medical Technology Assessment, Maastricht University Medical Centre, Maastricht, The Netherlands

${ }^{4}$ Department of Family Medicine, Maastricht University, Maastricht, The Netherlands ${ }^{5}$ Department of Methodology and Statistics, Maastricht University, Maastricht, The Netherlands

${ }^{6}$ Academic Collaborative Centre for Public Health Limburg, Heerlen, The Netherlands ${ }^{7}$ Department of Health Services Research, Maastricht University, Maastricht, The Netherlands

Acknowledgements We are grateful to all of the schools, the children and other collaborating partners participating in the project. We thank the $\mathrm{PhD}$ students and research assistants for their help in data collection.

Contributors NHMB, PvA, SPJK, HHCMS, MW, OCPvS and MWJJ were part of designing the intervention. $\mathrm{NHMB}, \mathrm{MO}$ and $\mathrm{MW}$ collected the data for the manuscript. NHMB and BW analysed the data. NHMB drafted and revised the manuscript. PvA, SPJK, HHCMS, M0, MW, OCPvS, BW and MWJJ critically reviewed the manuscript during the writing process. All authors have read and approved the final manuscript.

Funding This study was funded by the Limburg provincial authorities, project number 200130003, by FrieslandCampina, project number LLMV00, and by Maastricht University.

Competing interests None declared.

Patient consent for publication Not required.

Ethics approval Ethical approval was given by the Medical Ethics Committee Zuyderland located in Heerlen (MEC $14 \mathrm{~N}-142$ ).

Provenance and peer review Not commissioned; externally peer reviewed.

Data availability statement Data are available on reasonable request.

Open access This is an open access article distributed in accordance with the Creative Commons Attribution Non Commercial (CC BY-NC 4.0) license, which permits others to distribute, remix, adapt, build upon this work non-commercially, and license their derivative works on different terms, provided the original work is properly cited, appropriate credit is given, any changes made indicated, and the use is non-commercial. See: http://creativecommons.org/licenses/by-nc/4.0/.

ORCID iD

Marije Oosterhoff http://orcid.org/0000-0003-3644-4298

\section{REFERENCES}

1 Ogden CL, Carroll MD, Flegal KM. Epidemiologic trends in overweight and obesity. Endocrinol Metab Clin North Am 2003;32:741-60.

2 Strauss RS. Childhood obesity and self-esteem. Pediatrics 2000;105:e15-e.

3 WHO. Report of the Commission on ending childhood obesity. World Health Organization, 2016.

4 WHO. Obesity and overweight, 2018. Available: http://www.who.int/ en/news-room/fact-sheets/detail/obesity-and-overweight

5 Arcaya MC, Arcaya AL, Subramanian SV. Inequalities in health: definitions, concepts, and theories. Glob Health Action 2015;8:27106.

6 Schönbeck Y, Talma H, van Dommelen P, et al. Increase in prevalence of overweight in Dutch children and adolescents: a comparison of nationwide growth studies in 1980, 1997 and 2009. PLoS One 2011;6:e27608.

7 Marmot M, Allen J, Bell R, et al. Who European review of social determinants of health and the health divide. Lancet 2012;380:1011-29.

8 CBS, RIVM, The Netherlands Nutrition Centre. Kinderen eten te weinig fruit, groente en vis [Children eat to less fruit, vegetables and fish], 2017. Available: https://www.cbs.nl/nl-nl/nieuws/2017/46/ kinderen-eten-te-weinig-fruit-groente-en-vis

9 Volksgezondheidenzorg.info. Beweeggedrag kinderen [Physical activity behaviour of children], 2018. Available: https://www.volksgez ondheidenzorg.info/onderwerp/sport-en-bewegen/cijfers-context/ huidige-situatie\#node-beweeggedrag-kinderen

10 Craigie AM, Lake AA, Kelly SA, et al. Tracking of obesity-related behaviours from childhood to adulthood: a systematic review. Maturitas 2011;70:266-84.

11 Han E, Norton EC, Powell LM. Direct and indirect effects of body weight on adult wages. Econ Hum Biol 2011;9:381-92.

12 Stein D, Weinberger-Litman SL, Latzer Y. Psychosocial perspectives and the issue of prevention in childhood obesity. Front Public Health 2014;2.

13 Kelsey MM, Zaepfel A, Bjornstad P, et al. Age-Related consequences of childhood obesity. Gerontology 2014;60:222-8.

14 Lynch JW, Kaplan GA, Salonen JT. Why do poor people behave poorly? variation in adult health behaviours and psychosocial characteristics by stages of the socioeconomic lifecourse. Soc Sci Med 1997;44:809-19.

15 Suhrcke M, de Paz Nieves C. The impact of health and health behaviours on educational outcomes in high-income countries: a review of the evidence. Copenhagen, Denmark: World Health Organization, Regional Office for Europe, 2011.

16 Dooris M, Poland B, Kolbe L, et al. Healthy settings. global perspectives on health promotion effectiveness. Berlin, Germany: Springer, 2007: 327-52.

17 Langford R, Campbell R, Magnus D, et al. The who health promoting school framework for improving the health and well-being of students and staff. Cochrane Database Syst Rev 2011;1. 
18 Verrotti A, Penta L, Zenzeri L, et al. Childhood obesity: prevention and strategies of intervention. A systematic review of schoolbased interventions in primary schools. J Endocrinol Invest 2014;37:1155-64.

19 Cook-Cottone C, Casey CM, Feeley TH. A meta-analytic review of obesity prevention in the schools: 1997-2008. Psychol Sch 2009;46:695-719.

20 Oosterhoff M, Joore M, Ferreira I. The effects of school-based lifestyle interventions on body mass index and blood pressure: a multivariate multilevel meta-analysis of randomized controlled trials. Obes Rev 2016;17:1131-53.

21 Deschesnes M, Martin C, Hill AJ. Comprehensive approaches to school health promotion: how to achieve broader implementation? Health Promot Int 2003;18:387-96.

22 Darlington EJ, Violon N, Jourdan D. Implementation of health promotion programmes in schools: an approach to understand the influence of contextual factors on the process? BMC Public Health 2018;18:163.

23 Keshavarz N, Nutbeam D, Rowling L, et al. Schools as social complex adaptive systems: a new way to understand the challenges of introducing the health promoting schools concept. Soc Sci Med 2010;70:1467-74.

24 Moore GF, Audrey S, Barker M, et al. Process evaluation of complex interventions: medical Research Council guidance. BMJ 2015;350:h1258.

25 Hawe P, Shiell A, Riley T. Theorising interventions as events in systems. Am J Commun Psychol 2009;43:267-76.

26 Mason M. What is complexity theory and what are its implications for educational change? Educ Philos Theory 2008;40:35-49.

27 Stewart-Brown S. What is the evidence on school health promotion in improving health or preventing disease and, specifically, what is the effectiveness of the health promoting schools approach? Copenhagen, Denmark: World Health Organization, Regional Office for Europe, 2006.

28 Willeboordse M, Jansen MW, van den Heijkant SN, et al. The healthy primary school of the future: study protocol of a quasi-experimental study. BMC Public Health 2016;16:1.

29 Bartelink NHM, van Assema P, Jansen MWJ, et al. The healthy primary school of the future: a contextual Action-Oriented research approach. Int J Environ Res Public Health 2018;15:2243.

30 Young I, St Leger L, Buijs G. School health promotion: evidence for effective action background paper she factsheet, 2013.

31 Bartelink NHM, van Assema P, Jansen MWJ, et al. Process evaluation of the healthy primary school of the future: the key learning points. BMC Public Health 2019;19:698.
32 Bartelink NHM, van Assema P, Kremers SPJ, et al. One- and TwoYear Effects of the Healthy Primary School of the Future on Children's Dietary and Physical Activity Behaviours: A Quasi-Experimental Study. Nutrients 2019;11:689.

33 Gezondheidsraad. Dutch dietary guidelines 2015. The Hague, The Netherlands: Health Council of the Netherlands, 2015.

34 Vermeer AJM, Boot N, Hesdahl MH, et al. Lokale rapporten Volksgezondheid Toekomst Verkenning: Een nieuwe kijk op gezondheid in Heerlen, Kerkrade, Landgraaf en Brunssum; [Local reports on Public Health Development: A new perspective on health in Heerlen, Kerkrade, Landgraaf and Brunssum]. GGD Zuid Limburg: Geleen, 2014.

35 Shavers VL. Measurement of socioeconomic status in health disparities research. J Natl Med Assoc 2007;99.

36 Keij I. Hoe doet het CBS dat nou? Standaarddefinitie allochtonen [How does Statistics Netherlands do this? Standard definition of emigrants], 2000.

37 Cole TJ, Bellizzi MC, Flegal KM. Establishing a standard definition for child overweight and obesity worldwide: international survey. BMJ 2000;320:1240.

38 Volksgezondheidenzorg.info. Overgewicht kinderen [Overweight children], 2017. Available: https://www.volksgezondheidenzorg. info/onderwerp/overgewicht/cijfers-context/huidige-situatie\#nodeovergewicht-kinderen

39 Lipsey MW. Design sensitivity: statistical power for experimental research. Pugey, France: Sage, 1990.

40 Lister-Sharp D, Chapman S, Stewart-Brown S, et al. Health promoting schools and health promotion in schools: two systematic reviews. In: Database of Abstracts of Reviews of Effects (DARE): Quality-assessed Reviews [Internet]. London, UK: Centre for Reviews and Dissemination, 1999.

41 Hill JO, Wyatt HR, Melanson EL. Genetic and environmental contributions to obesity. Med Clin North Am 2000;84:333-46.

42 Kremers SPJ, de Bruijn G-J, Visscher TLS, et al. Environmental influences on energy balance-related behaviors: a dual-process view. Int J Behav Nutr Phys Act 2006;3.

43 Lorenc T, Petticrew M, Welch V, et al. What types of interventions generate inequalities? Evidence from systematic reviews: table 1. J Epidemiol Community Health 2013;67:190-3.

44 Boudewijns E, Pepels J, van Kann D, et al. Non-response and external validity in a school-based quasi-experimental study 'The Healthy Primary School of the Future': A cross-sectional assessment. Prev Med Rep 2019;100874. 